Note

\section{Flutter-stimulating Activities on Male Eri-Silk Moths, Philosamia cynthia ricini, of Four Geometric Isomers of 4,9-Tetradecadienyl Formate ${ }^{\dagger}$}

\author{
Ichiro Tomida, Kenji Iwakoshi, \\ Satoshi Kono, Takeshi Takahashi, \\ Taiki MATSUNAGA \\ and Hiroshi Kayahara
}

Laboratory of Biological Chemistry, Faculty of Agriculture, Shinshu University, Minamiminowa Kamiina, Nagano 399-45, Japan

Received August 27, 1986

As reported in the previous paper, ${ }^{1)}$ all four geometric isomers of 6,11-hexadecadienal exhibited flutterstimulating activities on male eri-silk moths, Philosamia cynthia ricini, to the same degree of $10^{-3} \sim 10^{-4} \mathrm{mg} / \mathrm{ml}$ minimum concentration. According to the additional private communication from Bestmann, ${ }^{2)}$ (4E,9Z)-4,9tetradecadienyl formate was also electroantennographically active, and this is an additional example of the fact that by exchanging the last $\mathrm{CH}_{2}$ group with an oxygen atom, i.e., structural variation from an aldehyde to a formate of the same chain length, a substance was yielded with almost the same EAG activity as the pheromone, ${ }^{3,4)}$ although in this case 6,11-hexadecadienal is not the true pheromone for this insect.

We were interested to learn about the respective flutter-stimulating activities of geometric isomers of 4,9-tetradecadienyl formate and their related compounds towards the same moths.

Four geometric isomers of 4,9-tetradecadienyl formate were prepared by formylating the respective 4,9tetradecadien-1-ols, which were obtained by the conventional methods as shown in the scheme. Condensation of 5-(2-tetrahydropyranyloxy)-pent-1-yne with 4-nonynyl or 4-nonenyl bromide, which was followed by hydrolysis, gave tetradeca-4,9-diyn-1-ol or -4-yn-9-en-1-ol, which were then hydrogenated $(E)$ - or $(Z)$-partially to respectively give each geometric tetradecadienol. The $\mathrm{C}_{14^{-}}$ alcohols and their formates thus obtained (the bp of these compounds lies in the range of $90 \sim 110^{\circ} / 0.2 \mathrm{mmHg}$ ) were purified by TLC-separation to give analytically pure substances, which were characterized spectroscopically (IR, NMR and MS). As listed in Table I, separate peaks were obtained by GLC.

All the compounds prepared were subjected to a biological test using the male eri-silk moths in the same way as described in the previous paper. ${ }^{1)}$ All the formates exhibited considerably large flutter-stimulating activities (Table I), but the corresponding alcohols gave much lower or practically no activity. The most powerful compound was found to be $(4 E, 9 Z)-4,9$-tetradecadienyl formate, and the order of decreasing activity in the formates was $4 E, 9 Z \gg 4 Z, 9 Z \geq 4 E, 9 E \geq 4 Z, 9 E \geq 9 Z, 4$-yne $>9 E, 4$-yne $>$ 4,9-diyne according to isomer. The same order was also confirmed electroantennographically.

These formates are fairly stable during storage in comparison with the hexadecadienals ${ }^{1)}$ and, therefore, can be conveniently used as standard substance to study the activities of other compounds.

$$
\begin{gathered}
\mathrm{CH}_{3}-\left(\mathrm{CH}_{2}\right)_{3}-\mathrm{C} \equiv \mathrm{C}-\left(\mathrm{CH}_{2}\right)_{3}-\mathrm{Br} \\
\mathrm{CH}_{3}-\left(\mathrm{CH}_{2}\right)_{3}-\mathrm{CH}=\mathrm{CH}-\left(\mathrm{CH}_{2}\right)_{3}-\mathrm{Br} \\
\mathrm{CH}_{3}-\left(\mathrm{CH}_{2}\right)_{3}-\mathrm{C} \equiv \mathrm{C}-\left(\mathrm{CH}_{2}\right)_{3}-\mathrm{CH} \equiv \mathrm{C}-\left(\mathrm{CH}_{2}\right)_{3}-\mathrm{OH} \quad \text { or } \\
\left.\mathrm{CH}_{3}-\left(\mathrm{CH}_{2}\right)_{3}\right)_{3}-\mathrm{CH}=\mathrm{CH}-\left(\mathrm{CH}_{2}\right)_{3}-\mathrm{C} \equiv \mathrm{C}-\left(\mathrm{CH}_{2}\right)_{3}-\mathrm{OH} \quad \downarrow_{2} \\
\mathrm{CH}_{3}-\left(\mathrm{CH}_{2}\right)_{3}-\mathrm{CH}=\mathrm{CH}-\left(\mathrm{CH}_{2}\right)_{3}-\mathrm{CH}=\mathrm{CH}-\left(\mathrm{CH}_{2}\right)_{3}-\mathrm{OH} \\
\mathrm{CH}_{3}-\left(\mathrm{CH}_{2}\right)_{3}-\mathrm{CH}=\mathrm{CH}-\left(\mathrm{CH}_{2}\right)_{3}-\mathrm{CH}=\mathrm{CH}-\left(\mathrm{CH}_{2}\right)_{3}-\mathrm{OCHO} \\
\text { THP }=\text { tetrahydropyrany } 1
\end{gathered}
$$

SCHEME Syntheses of Tetradeca-4,9-diyn-, -9-en-4-yn- and 4,9-dien-1-ols and Their Formates. 
Table I. Geometrical Purity, Relative $t_{R}$-Values and Flutter-Stimulating Activities on Male Eri-Silk Moths of the Prepared $\mathrm{C}_{14}$-Alcohols and Their Formates

\begin{tabular}{|c|c|c|c|c|c|c|}
\hline Compound & \multicolumn{4}{|c|}{$\begin{array}{c}\text { Contamination of geometrical isomers }{ }^{a} \\
(\%)\end{array}$} & Rel. $t_{R}^{b}$ & $\begin{array}{l}\text { Activity }^{c} \\
(\mathrm{mg} / \mathrm{ml})\end{array}$ \\
\hline \multirow{3}{*}{$\begin{array}{l}\text { Tetradeca- } \\
\text { 4,9-diyn-1-ol }\end{array}$} & & & & & & \\
\hline & & & & & 1.75 & - \\
\hline & \multicolumn{2}{|c|}{$E$} & \multicolumn{2}{|c|}{$Z$} & & \\
\hline (E)-9-en-4-yn-1-ol & \multicolumn{2}{|c|}{ - } & \multicolumn{2}{|c|}{4.4} & 1.233 & - \\
\hline (Z)-9-en-4-yn-1-ol & \multicolumn{2}{|c|}{10.5} & \multicolumn{2}{|c|}{-} & 1.257 & - \\
\hline & $E, E$ & $Z, E$ & $E, Z$ & $Z, Z$ & & \\
\hline$(4 E, 9 E)-4,9$-dien-ol & - & 0 & 0 & 0 & 0.9481 & - \\
\hline$(4 Z, 9 E)-4,9$-dien-1-ol & 0 & - & 0 & 4.7 & 0.9578 & - \\
\hline$(4 E, 9 Z)-4,9$-dien-1-ol & 1.0 & 11.5 & - & 1.4 & 0.9820 & 1 \\
\hline$(4 Z, 9 Z)-4,9$-dien-1-ol & 8.2 & 6.4 & 8.2 & - & 1.000 & 1 \\
\hline \multirow[t]{2}{*}{ 4,9-diynyl formate } & & & & & 1.683 & $10^{-1}$ \\
\hline & \multicolumn{2}{|c|}{$E$} & \multicolumn{2}{|c|}{$Z$} & & \\
\hline (E)-9-en-4-ynyl formate & \multicolumn{2}{|c|}{ - } & \multicolumn{2}{|c|}{4.6} & 1.167 & $10^{-1}$ \\
\hline \multirow[t]{2}{*}{$(Z)-9-$ en-4-ynyl formate } & \multicolumn{2}{|c|}{10.4} & \multicolumn{2}{|c|}{-} & 1.203 & $10^{-2}$ \\
\hline & $E, E$ & $Z, E$ & $E, Z$ & $Z, Z$ & & \\
\hline$(4 E, 9 E)-4,9$-dienyl formate & - & 4.0 & 0 & 0.4 & 0.896 & $10^{-2}$ \\
\hline$(4 Z, 9 E)-4,9$-dienyl formate & 8.8 & - & 4.0 & 0 & 0.914 & $10^{-2}$ \\
\hline$(4 E, 9 Z)-4,9$-dienyl formate & 17.7 & 0 & - & 0.6 & 0.942 & $10^{-4}$ \\
\hline$(4 Z, 9 Z)-4,9$-dienyl formate & 2.1 & 12.3 & 7.7 & - & 0.968 & $10^{-2}$ \\
\hline
\end{tabular}

a Analyzed by GLC using an SS-capillary column of $50 \mathrm{~m} \times 0.24 \mathrm{~mm}$ (Shimazu Co.) at $180^{\circ} \mathrm{C}$, using He carrier gas $\left(1.2 \mathrm{~kg} / \mathrm{cm}^{2}\right.$ at the inlet) and an FID. The alcohols were analyzed in the form of their acetate.

b $(4 Z, 9 Z)-4,9-$ Tetradecadienyl acetate $=1.000\left(t_{R}=14.45 \mathrm{~min}\right)$.

c $50 \%$ effecitive minimum concentration ( $c f$. ref. 1$)$ : - , not active at $1 \mathrm{mg} / \mathrm{ml}$.

Acknowledgments. The authers are indebted to Professor H. J. Bestmann (Erlangen University) for his kind information about the antennographic studies, and to Professor H. Ishizaki (Nagoya University) for his kind supply of eri-silk moth pupae. This work was partly supported by a Grant-in-Aid for Scientific Research (No. 60560130) from the Ministry of Education, Science and Culture of Japan, and also partly by financial help from the Science Promoting Association of Nagano Prefecture.

\section{REFERENCES}

1) I. Tomida, I. Umeda, I. Kudo and H. Kayahara, Agric. Biol. Chem., 50, 2143 (1986).

2) H. J. Bestmann, Private communication (1982).

3) E. Priesner, M. Jacobson and H. J. Bestmann, $Z$. Naturforsch., 30c, 283 (1975).

4) Anonymous, Chem. Eng. News, 50 (49), 19 (1972). 